Revista de la red interuniversitaria de estudios sobre las literaturas rioplatenses contemporáneas en Francia

16 | 2017

Esnobismos

\title{
Un lirismo sine nobilitate : moda, mundanidad y sociolectos como inscripciones del presente en la poesía de Arturo Carrera.
}

\section{Gerardo Jorge}

\section{OpenEdition}

\section{Journals}

Electronic version

URL: http://journals.openedition.org/lirico/3730

DOI: $10.4000 /$ lirico.3730

ISSN: 2262-8339

\section{Publisher}

Réseau interuniversitaire d'étude des littératures contemporaines du Río de la Plata

\section{Electronic reference}

Gerardo Jorge, « Un lirismo sine nobilitate : moda, mundanidad y sociolectos como inscripciones del presente en la poesía de Arturo Carrera. », Cuadernos LIRICO [En línea], 16 | 2017, Puesto en línea el 06 octubre 2017, consultado el 06 mayo 2019. URL : http://journals.openedition.org/lirico/3730 ; DOI 10.4000/lirico.3730

This text was automatically generated on 6 May 2019.

\section{$\Theta \Theta \Theta \Theta$}

Cuadernos LIRICO está distribuido bajo una Licencia Creative Commons Atribución-NoComercialSinDerivar 4.0 Internacional. 


\title{
Un lirismo sine nobilitate : moda, mundanidad y sociolectos como inscripciones del presente en la poesía de Arturo Carrera.
}

\author{
Gerardo Jorge
}

1

Hay un poema de Arturo Carrera que se titula « En una disco » que resulta emblemático, por varios motivos, de algunas tensiones características del gran proyecto poético de su obra, al menos de la etapa que abre la publicación de Arturo y yo en $1984^{1}$. El poema está en el libro La banda oscura de Alejandro, publicado en 1994, fecha que constituye un momento particular tanto para Carrera (que entonces ya ocupa un lugar central en términos de reconocimiento y que seguirá en ascenso en los años siguientes en la consideración de lectores y colegas) como para la poesía argentina (porque la década del noventa es el tiempo de emergencia de la corriente de ruptura que se dará en llamar « poesía de los noventa »). «En una disco » es un poema interesante porque permite entrar en la obra de Carrera a través de algunos de los elementos que la convirtieron tanto en una de las más relevantes de la poesía latinoamericana de las últimas décadas como en un objeto extraño, indócil a las nomenclaturas y adscripciones una vez abandonada la etapa más neobarroca. El poema reconstruye una escena que sucede justamente en una discoteca, en la cual el yo (representación del poeta en este caso ${ }^{2}$ ) dialoga con Rosario Bléfari, una actriz y cantante que -a principios de los años noventa- está en pleno ascenso en su trayectoria hacia convertirse en figura de culto de la música underground local ${ }^{3}$. Bléfari es mencionada con su nombre propio varias veces a lo largo de un texto que reconstruye un diálogo que tiene lugar al ritmo del baile y cuya impronta está marcada por el juego y el coqueteo. En la conversación la cantante habla acerca de una charla que el poeta dio a la cual ella asistió como público. En un recurso habitual en la poesía de 
Carrera, la voz de ella es reiteradamente citada entre comillas y se mezcla, desde el punto de vista de ese yo, con las imágenes y sensaciones que surgen de las luces (« un arco iris de láser / cortaba en dos nuestros cuerpos »), los sonidos (« Hablábamos otra vez a los gritos pero / ya creíamos susurrar $»^{5}$ ) y el movimiento. El diálogo incluye giros coloquiales (Bléfari dice "chabón" y "boludo») que se recortan sobre el tono moroso y mucho menos oral de las palabras que el yo enhebra como observaciones o reflexiones al margen del diálogo. El yo se vale, a su vez, de un préstamo del inglés (la voz de Bléfari « se iba y venía / como una vocecita en fading... $»^{6}$ ) y deja leer una actitud de entrega embelesada ( "Oh única muchachita / en esa multitud que no me habla, ella me habla $»^{7}$ ) al momento con la cantante, mientras ella bromea sobre «el imperio de los vestidos, / el de los frufrúes, el de los pliegues y tactos $»^{8}$. El cierre del poema trae la mención de otro nombre propio, el de Gaspar Noé9 , hijo del artista argentino Luis Felipe Noé. Y es la palabra de Noé, quien por entonces es un cineasta de cortos y mediometrajes pero ya ha sido premiado en Cannes, la que clausura la aventura erótica, ensoñada y melancólica que narra el poema : « Parecés un negrito $»^{10}$, le dice al yo (al poeta) en el último verso.

2 «En una disco » es singular porque condensa muchos elementos que forman parte de los poemas de Carrera: la inscripción de nombres propios de personas «reales », muchas veces artistas (en otros poemas aparecen los pintores Marcia Schvartz, Alfredo Prior, Guillermo Kuitca), escritores (César Aira, Emeterio Cerro), cantantes, cineastas o músicos ; los giros coloquiales pero sobre todo sociolectales, palabras de uso habitual entre los jóvenes («re », «boludo », « chabón »); los préstamos de otras lenguas que interrumpen un español muy amplio lexicalmente; todos elementos -a los que podríamos sumar las citas y epígrafes de autores en boga como Gilles Deleuze y Pascal Quignard- que podríamos caracterizar como "materiales de presente $»^{11}$ y que señalan una intensa atención hacia cierta contemporaneidad, hacia el mundo de los jóvenes e incluso, por qué no, la exhibición de una determinada participación social vinculada al arte, al ocio y (en este caso) a la noche ${ }^{12}$. Estas marcas son interesantes porque son recurrentes en Carrera, volcada como está su poesía a la evocación de escenas y sensaciones muchas veces epifánicas; pero lo son más todavía porque pueden leerse en relación con algunos discursos que se produjeron a propósito tanto del neobarroco en general como de Carrera en particular, según el caso. Y me refiero a la mirada que tachó de «frívola y " superficial » a la primera poesía neobarroca (son términos con los que García Helder se refería al primer tramo de las obras de Carrera y Perlongher, entre otras, en «El neobarroco en Argentina ", en $1987^{13}$ ), pero no sólo a esa mirada crítica de un modo de usar el lenguaje haciéndolo proliferar desde lo sonoro, sino también a otras caracterizaciones, hechas incluso desde la aprobación, como la de Fogwill quien en una entrevista en el año 1993, se refería a Carrera como un poeta " admirable » pero decía que lograba serlo pese a ser un "dandy", un "personaje de superficie absoluta», un " cholulo " y un « cortesano $~^{14}$, estableciendo una antinomia entre esas maneras de ser supuestamente atribuibles a Carrera y el carácter logrado de la obra. Ese dandismo sería un obstáculo, según Fogwill, para producir una obra con valor de verdad, pero Carrera sería la excepción : alguien superficial cuya " poesía es una poesía de verdad » donde « no hay sentimiento fabricado, ni citado $»^{15}$. Más cerca en el tiempo, en el prólogo a la poesía reunida de Carrera, Sergio Chefjec caracteriza al poeta como de una «timidez mundana » ${ }^{16} \mathrm{y}$ en la reseña de Valeria Melchiorre a ese libro se subrayan las habilidades sociales del autor al tiempo que se dice que en su obra « los últimos gritos de la moda están a la orden del día, al menos proporcionando un registro discursivo, un vocabulario ${ }^{17}$. Moda, 
mundanidad, superficialidad: más allá de lo que hay -toda vez- de peyorativo y excesivo en algunos de estos términos, se agrupan y dan cuenta de la percepción de algo, de un elemento que estaría en la poética (y, algunos se aventuran, en la persona) de Carrera, que resulta incómodo y se vuelve por eso un eje para interrogarla. La marca de que algo llama la atención y acaso incomoda puede rastrearse en que el planteo de la discoteca como topos para un poema, en línea con las voces citadas, ocupó el título y buena parte del desarrollo de la reseña que Diario de Poesía dedicó a La banda... : Martín Prieto la tituló « Ortiz en una disco $»^{18}$. ¿Cómo leer esas referencias a una sociabilidad "privilegiada", entonces, la inclusión de formas del habla de los jóvenes o los guiños a lecturas en boga en una obra que, por lo demás, hay que considerar lírica y que vuelve una y otra vez sobre grandes temas de la historia de la poesía como el eros, la muerte y la infancia? Lejos de lo que una lectura apresurada podría plantear (la idea de que la recurrencia de estos elementos implica una aceptación de lo dado y aprobado en el presente como confín para el imaginario poético), en Carrera el trabajo con estos materiales es fundamental para la constitución de una forma de lirismo que evada los lugares comunes en los que dicha búsqueda ha caído con frecuencia en la poesía argentina desde mediados del siglo XX.

\section{2}

3 La obra de Carrera, al menos desde Arturo y yo, puede leerse como « lírica », en el sentido que el término adquiere en la modernidad ${ }^{19}$ : es decir, como una poesía que trabaja con el yo, que aborda experiencias personales, pero sobre todo que aborda cuestiones como el eros, la memoria, las emociones, lo íntimo (materiales clásicos de la poesía mélica y lírica antigua). Sin embargo, si bien es cierto que esto la caracteriza, hay un problema : lo que llamamos «lírica " adquirió en la modernidad un carácter amplio y prácticamente se llegó a solapar con el término " poesía ", pero las obras que han tendido a denominarse de este modo han aparecido en varios momentos de la historia como uno de los reductos más marcadamente cerrados a los «materiales de presente » que puedan encontrarse en la producción poética del siglo pasado. Si nos restringimos a la poesía argentina, los autores de la "generación del cuarenta ", por ejemplo, cultivaron obras que comparten ejes e intereses con la de Carrera (el pasado, el campo, la infancia) valiéndose de lo que Eduardo Milán llamó « un lenguaje poético que se pretende ahistórico, cuya única noción de subjetividad es un cruce entre el confesionalismo sentimental y la práctica destemplada de una formalización a la que considera atemporal $»^{20}$. La identificación entre la práctica poética y lo que ya fue concebido como poético resulta ideológica en estos esquemas que imaginan a la poesía como algo separado de las transformaciones de la lengua en su uso popular y cotidiano y como lo opuesto a la falsedad dominante de esos usos y otros (la publicidad, el periodismo, por ejemplo). Esta mirada sustenta una escritura abundante en citas a los clásicos, de una atención obsesiva hacia el pasado y que se vale de un léxico y unas técnicas y formatos reconocibles a priori como « poéticos » (la métrica, la rima, el cultivo incansable del soneto entre otros géneros de poema). Y en el contexto en el que aparece «En una disco » de Carrera, esta concepción se verá pronto actualizada en la obra de autores ligados a la revista Hablar de Poesía que, comandada por Ricardo Herrera y Luis Tedesco, se lanza en $1999^{21}$. Más allá de que el panorama y las tendencias de la poesía argentina de los años ochenta y noventa son objetos de tal complejidad como para requerir estudios puntuales y admiten distintas formas de plantearse ${ }^{22}$, Hablar de Poesía constituye sin duda uno de los puntos relevantes de ese 
mapa de poéticas y, además, nos interesa porque es el que reivindica el término « lírica » que usé para referirme a la obra de Carrera. La concepción de Hablar, en general, implica un esquema en el que los «materiales de presente» y -mucho más- el tratamiento celebratorio de los mismos, aparecen contraindicados como lugares en los que la belleza fracasa $^{23}$. Una voz depurada, resistente a los mandatos de una época donde la poesía es percibida en posición de exilio social, define así los contornos de poéticas que buscan remontarse hacia cierta universalidad o atemporalidad.

En el otro extremo de esos años noventa, pero también como efecto de las discusiones acarreadas desde el regreso a la democracia, hay que situar a los autores de la llamada " poesía de los noventa ». Promocionados varios de ellos por el Diario de Poesía (1986-2011), eje fundamental del período contra el cual se constituyó Hablar de Poesía, y organizados en torno a revistas y editoriales autogestionadas, la mirada que sostuvieron sus autores, no siempre coincidente con la de quienes integraban el Diario de Poesía, propuso poéticas edificadas desde una relación intensa, crítica y/o expresiva con el Zeitgeist ${ }^{24}$, impugnando el valor otorgado casi per se a la tradición y al pasado por poetas como los que se reunirían en Hablar de Poesía. Estos poetas, bien que de un modo problemático, se propusieron como herederos de lo más "antipoético " de la tradición argentina y latinoamericana, impugnaron el lenguaje culto, las formas clásicas, todo aquello que tuviera tufillo a " poesía " en el sentido elevado del término y que se pretendiera separado de las condiciones materiales de producción. En sus obras, la referencia a personas reales, la mención del mundo de la moda, de fiestas pero también de sitios urbanos degradados y reconocibles, de nombres de la política y/o los medios de comunicación, es decir, de un presente rabiosamente reconocible como tal, es constante. En Hablar de Poesía y los " poetas de los noventa " podríamos ver dos extremos en términos de la forma de concebir la poesía en relación con la tradición, el presente y los tonos y registros.

5 Si puede considerarse que Carrera ofició de promotor de parte de la "poesía de los noventa » como compilador de la antología Monstruos editada en 2001, su obra ocupa sin embargo un lugar incómodo en este mapa balizado por esa « lírica » cerrada al presente, trascendental y de un cuño formalista abocado a la tradición, por un lado; y por las poéticas del Zeitgeist, en muchas de las cuales el trabajo sobre "materiales de presente » aparece como confín y deja poco espacio para la inflexión íntima o lírica -idea que quedó sellada en la provocativa declaración del poeta Alejandro Rubio « la lírica está muerta » ${ }^{25}$ por otro. Tampoco, es obvio, puede ubicarse a Carrera cerca del objetivismo, corriente que agrupó a algunos de los editores del Diario de Poesía y que tuvo uno de sus manifiestos en el citado texto de Helder de 1987. Su poesía puede considerarse lírica en tanto se aboca a cuestiones personales y atemporales como el erotismo y las sensaciones, por ejemplo, y también por su registro general. Leamos dos inicios de poemas de La banda... :

Banda de primavera

Iris de la custodia : soledad,

De tal modo mi mente

esas miradas soledades de confín arroja

más allá, más allá de los desiertos. ${ }^{26}$

(...)

Leve retina

Otro tiempo debería de comenzar,

el tiempo de escuchar latir,

en la clepsidra turbulenta,

el otro corazón imaginado :27

(...) 
Carrera se vale de hipérbatos, cultismos y elisiones con frecuencia y también de la versificación clásica (el inicio del bello poema « Dioses impares », del mismo libro, es un musical pareado de endecasílabos «oculto » a nivel visual por usar números para las edades en el primer verso : « Fermín (14) y yo (41) / varones de la casa este verano" ${ }^{28}$ ). Sin embargo, se coloca lejos de todo ideal de perfección técnica al eludir las formas fijas donde esa gimnasia se prueba, y los giros coloquiales y marcas de actualidad la separan de la concepción de la lengua poética como cosa «pura» que rechaza "el vértigo publicitario de la época» del que hablaban Herrera y Tedesco, desestabilizando su pertenencia al paradigma lírico del momento. La pregunta entonces es cómo funcionan en la obra de Carrera esa suerte de «manchas » que la hacen inadecuada para la lírica contemporánea y cómo responde a los problemas que se plantearon para la poesía durante y después de la dictadura en Argentina: qué hacer con la realidad, con el presente, con la memoria, con la política, con el lenguaje.

\section{3}

7 Para abordar esto hay que considerar una serie de aspectos generales de la obra de Carrera. Al enfrentarnos a las páginas de sus libros, sobre todo a partir de Arturo y yo (1984), nos encontramos con un trabajo sobre la dimensión visual de versos y estrofas que -personal interpretación de la revolución mallarmeana tamizada por el concretismo de mediosiglo- plantea un tipo de organización del texto en la página que remite a primera vista a una figura de lo "abierto », donde las palabras flotan y se escanden -se diría- de un modo pausado, discontinuo. Su forma de organizar el texto en la página transitó por una idea de mosaico cercana al concretismo en Oro (1975) y, más cerca en el tiempo, llegó a la prosa en El Coco (2003) y en Potlatch (2004), pero se estabilizó en el esquema de una serie de formas estróficas irregulares, con grupos que van de los dos o tres (característicamente) hasta los cinco o seis versos, puntuadas o separadas por un triple espacio que las dispersa en una página con importantes blancos que se semiotizan como tiempos de silencio y que también trasuntan un ritmo disgregado y meditativo apto para derivas y discontinuidades en el discurso. La voz que se constituye o fluye por ese cauce resulta proclive a los saltos y digresiones. Esta forma estrófica característica es verificable en el poema « En una disco » del cual comenzamos hablando :

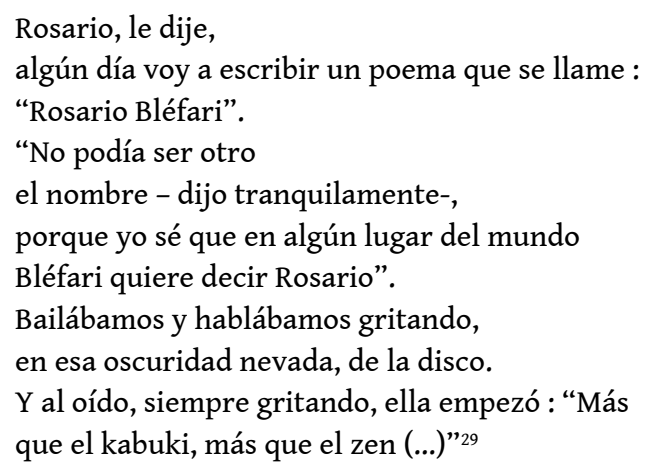

8 Ahora bien, este ordenamiento se presenta recurrentemente en concurso con otros procedimientos que introducen desconcierto como el uso rarificado de la puntuación, por el cual a veces se hace difícil balizar el comienzo y final de frases y oraciones o se retoma con minúscula tras un punto: 
En ese plancton de membranas invisibles

tan en la punta de una lengua familiar,

conocida...

los límites y contactos se cortan

en unos débiles colores.

el agua apenas los tiñe ensangrentándolos

Sabores confusos de lo inadvertido

que baja en una línea tensísima,

llamada : "la línea tensada por el infinito"

(en la armonía de pulir... no sé... qué...

... ¿diamantes con carbones?)

pero el sapito no. ${ }^{30}$

9 Hay, además, como se advierte en este fragmento, un constante tono interrogativo que modaliza lo dicho de una forma poco clara o asertiva. De la misma manera, el espaciarse de versos y estrofas sirve a cambios de tema, deslizamientos digresivos que muchas veces consisten en la interrupción de una voz por otra, como si un rumor (palabra cara a Carrera) fuera y viniera alrededor de la voz principal -no entrecomillada. Así en este poema de La inocencia :

Pero sigue preguntando. ¿Qué es un beso?

¿Por qué perdido en la clámide

su lucecita de rojizo vino enciende?

¿Quién es el roedor

de su dolor mezquino?

“... el DJ estaba re de pala,

su piel parecía de mármol, pero mármol

que se ablandara apenas..." ${ }^{31}$

10 Si aquí se nota cómo esos usos sociolectales (" el DJ estaba re de pala ») aparecen a veces como interrupción de otra voz que -en el otro extremo del registro- pronuncia la palabra « clámide ", hay también recursos que aparecen como formas de señalar un carácter incompleto del texto, haciéndolo lucir como un escolio : el uso de barras y líneas en La partera canta (1982) y Mi padre (1985) ya era una forma de esto, pero en la etapa que abre Arturo y yo (1984) son los puntos suspensivos y los paréntesis los que aluden a la fragmentariedad de lo presentado, mostrando a menudo al texto como parte de algo más grande (quizás ese murmurar continuo de voces) de lo cual se lo habría extraído. El comienzo de «Laguna Bonifiglio » (Children's corner, 1989) es un ejemplo de esto, señalando un decir ausente que antecede a la irrupción de la voz del poema :

(...)

No nos bañamos cuatro veces

en la misma laguna.

Ni explicaba que soñaba.

Ni contaba en sueños.

(Ni los olvidaba, memoria olvidadiza,

ni los memorizaba...) $)^{32}$

11 La conjugación de estos recursos produce varios efectos pero tiende, en general, a colocar a las voces, dichos y personajes que aparecen en los poemas en un hábitat difuso, pronto a desvanecerse de golpe por una pausa, un cambio de tema, una interrogación o la irrupción de otra escena en poemas largos que el poeta ha vinculado con la noción antigua de "carmen perpetuum"

Ahora bien, si el trabajo estrófico y gráfico sirve a estos desplazamientos y alude a esa figura de lo abierto e incompleto, no menos importante es el hecho de que cada libro de 
Carrera se desarrolla a partir de lo que podríamos denominar un plan conceptual y una investigación. Se trata de libros que tienen una arquitectura que los sitúa entre el archivo y la monografía, dado un ordenamiento interno que normalmente incluye secciones (un prólogo, epígrafes, la disposición en varias partes tituladas cada una a su vez con sus respectivos epígrafes, y el uso de notas al pie, entre otros recursos) y una fijación de los temas hecha en el prólogo, el título o la contratapa : en Potlatch (2004) se trata del dinero; en Las cuatro estaciones (2008), de la región de la infancia y del paso del tiempo ; en Noche y Día (2005), de las formas actuales del carpere, del gozo cotidiano ; en Mi padre (1985), de la paternidad; en La partera canta (1982), de la maternidad y el nacimiento ; en el Tratado de las sensaciones (2002), de la memoria familiar y migratoria; en Oro (1975), de las culturas precolombinas y sus poéticas, y así. En ese sentido, los libros aparecen como maquetas que abordan cuestiones desde múltiples ángulos, donde siempre hay paratextos que operan introduciendo discursos « ajenos » como apoyaturas para poemas en los que -a su vez, veremos- resuenan muchas voces.

13 Estos dos marcos estructurales se articulan para dar lugar a lo que acaso sea más importante que es un amplio entramado de voces, léxicos, fuentes, referencias y entonaciones donde el arco de lecturas y universos referidos es tan amplio que logra que ninguno predomine totalmente sobre el conjunto, sino que se maticen en un movimiento levemente sinfónico coordinado por la voz de un yo que funciona -al interior y acaso al exterior de la obra- como imagen de un poeta testigo, escucha y observador en general, a mitad de camino entre el sociólogo, el antropólogo y el curioso. Ese yo va de la discoteca al campo, lee a los teóricos celebrados en su tiempo, a los clásicos de la tradición poética y filosófica, y mezcla o remixa las voces de tías y abuelas con las de niños, poetas, filósofos y amigos artistas. Por eso, los tonos y referencias de «En una disco ", se mezclan con otros discursos y ambientes, se interrumpen, emergen y se desdibujan. Si se tratara de observar cómo está poblado un virtual territorio de los poemas de Carrera, no estarían sólo sus amigos escuchando música de moda, no aparecerían sólo Georges Bataille, Agnes Martin y Olivier Messiaen como marcas de sofisticación y de un "estar al día", sino que se mezclarían con un universo familiar (un padre, una madre, primos, hijos, tías, abuelos) y también con personas anónimas de pueblo que son mencionadas, citadas o referidas a través de sus dichos o en inventarios de apellidos (italianos y españoles casi siempre) que conforman una historia lingüística y migratoria de un cronotopo determinado (porque la poesía de Carrera está casi siempre situada entre Cnel. Pringles y Buenos Aires). Esto conforma la (re)presentación de un continuo donde lugares, tiempos y cotidianidades diferentes se funden. Y lo mismo resulta aplicable a las fuentes y los registros de lengua que también abundan diversos dentro de uno coordinante (la voz carreriana) que los va introduciendo y que, como generalidad, se aleja -aunque no al extremo- de lo coloquial.

En epígrafes, prólogos, notas al pie y citas incluidas en los poemas, Carrera mezcla esas lecturas en boga (de éstas, la obra de Deleuze es la más citada) con otras que cuadrarían perfectamente en el imaginario de la lírica refractaria al presente (clásicos griegos y latinos de Platón a Safo y de Demócrito a Hesíodo y Catulo, y también poetas modernos como Rilke). A su vez, y esto acaso constituya la nota más personal, esas referencias se cruzan con textos que provienen de revistas científicas, diccionarios, enciclopedias, libros de arqueología, botánica o sociología, para conformar un entramado algo indeterminado que contornea los temas de cada libro. En La banda..., para referirse al fenómeno perceptual del arco iris que da título al libro, el poeta coloca epígrafes de Thoreau, Emerson y Dickinson, en continuo con un fragmento de un libro de teoría del color de 
Paul Klee, una cita de Plutarco, un extracto de un artículo de una revista científica barcelonesa y un fragmento de una historia de la música del compositor y musicólogo brasileño José Miguel Wisnik. Casi como un vórtice antropófago de discursos, el poeta monta y hace reaccionar miradas de épocas y paradigmas diversos como fondo para los poemas, manteniendo un espacio coral dentro y alrededor de los poemas que matiza todo monologismo o efecto de palabra única y autosuficiente.

Pero lo más interesante sucede acaso en el plano microscópico de los registros de lengua. Ese modo de decir de Carrera de tono ligeramente elevado, apartado del habla cotidiana por léxico y por la composición barroca de sus frases, es constantemente interferido por otras voces e incluso muchas veces se desliza en transiciones difíciles de fijar hacia ellas, ya que las introduce muchas veces mediante la cita de sus dichos ( dijo ", « dijiste ») pero también con un uso algo inestable del entrecomillado que otras tantas marca la pertenencia de una voz a un tercero pero evade la atribución, permaneciendo el emisor como una incógnita al punto de que el todo textual se (con)funde en una misma voz múltiple. Con estos procedimientos, Carrera da entrada a oralidades que pueden ser tanto el habla de los niños,

Y vos dijiste, extasiado, olvidándome

(señalando una chispita que ardía

más que intermitentemente) :

“¡Ahí vive el viejo !, ¿no, pá ?”

“¿Molestamos? - dijo Luciana-. Y

agregó : “¡Tonto, vos no conocés todo

nuestro campo!"35

como un chisme o testimonio tomado a personas de diversa extracción social y generacional en las « datas » en prosa en Potlatch (2004) ${ }^{36}$. Los usos sociolectales del habla joven pueden aparecer a veces provocando humor y desconcierto (como en un fragmento de La banda... donde choca la expresión coloquial « un toco » con abstracciones como « invisibilidad y vacío »),

-Lo llaman “camuflaje sónico", dijo Claudio Baroni

(músico).

Pero es pura "invisibilidad", mirá,

un toco de invisibilidad

y vacío... ${ }^{37}$

y otros giros orales casi universales como el « ya sé » aparecen para interrumpir el inicio de lo que podría ser de una invocación en tono elevado en la cual el poeta se dirige a un público colectivo : «Vengan a Pringles, -ya sé, / no es Delfos. / Pero a tres cuadras de mi casa, / por la calle Stegmann, / hacia el sur, / está el arroyo. $»^{38}$ Otras veces, ese descenso de lo « alto » llega a niveles de lengua que pulverizan toda noción de « buen gusto » o idea de « belleza » fundada en el escamoteo de lo dicho y en la depuración lexical :

En la primera cola tal vez, antes de confesarme. Y esperaba, como los otros niños

el momento de disolver con palabras

en la oración la palabra y

el pecado. $Y$ mientras esperaba

me cagué. El sorete era duro

y se sostuvo sin deslizarse

entre el calzoncillo de frisa y

el borde del pantalón (que era corto

todavía). Y me confesé, cagado, 
y me despedí de mis amigos de catecismo,

cagado." 39

$18 \mathrm{Al}$ aparecer como incrustaciones o desplazamientos en un conjunto que incluye otras referencias y registros, remisiones a la antigüedad griega, préstamos no sólo del inglés sino también de lenguas más tradicionales como el latín, y un marco general de dicción lírica algo barroca, lo que queda claro es que Carrera esboza una voz que hace uso de tonos y recursos genéricos de la tradición pero que es constantemente interrumpida por otros registros y referencias que la alejan de la pureza y la muestran como permeable, buscando una y otra vez conectar lo cotidiano y familiar con tiempos míticos y remotos pero estando fuertemente inscripta en el presente histórico de su formulación. El gesto de Carrera consistiría así antes en un ritmar y unir voces y materiales, distanciándose y acercándose alternativamente a ellos, que en un típico monólogo interior de poeta lírico con una unidad clara de tono, léxico e imaginario. La voz de Carrera "no es una voz 'limpia' ", como ha señalado Sergio Chefjec $^{40}$. Sin renunciar a la idea de que un poeta construye una " voz » en sus poemas (una cierta estabilidad en sus modos de decir que propone como identidad), Carrera inventa sin embargo una voz atravesada por ecos y conversaciones ajenas, una voz lírica en contexto, por decirlo de algún modo, hospitalaria al rumor social. Esta es acaso una de las características más singulares de su poesía : sería difícil encontrar, en la poesía argentina, una voz roturada del modo que lo está la de Carrera, una voz tan lírica, tan capaz de construir una mirada y un universo personales y emotivos, y a la vez tan poco monológica, tan poco cerrada sobre sí misma, tan poco solipsista ${ }^{41}$.

\section{4}

El efecto de la inclusión en la obra de Carrera de lo que la conecta con la " moda ", así, supone acentuar esa impureza y, junto con otros recursos, impedir la institución de una voz homogénea, asertiva, autosuficiente. Por otra parte, esos elementos implican también una toma de posición frente a la temporalidad histórica: marcas del presente en una poética orientada a la memoria y las sensaciones, inscriben el ejercicio lírico en un tiempo y lugar determinados, dotándolo de mayor naturalidad y verosimilitud. Por otra parte, forman una red de sentido en clave autobiográfica (muchos de los personajes que se mencionan son amigos del poeta ${ }^{42}$ ) sin que ese gesto conduzca a una mirada solipsista ni tenga como efecto principal la mitificación de la figura del autor. Hay una voluntad de actualidad en Carrera, un desprecio por la mojigatería que indica separar a los poemas de la coyuntura para situarlos en un plano ideal o abstracto. Esa voluntad se manifestó tempranamente cuando incluyó la mención de marcas comerciales como el « Fairlane »o el « jugo Tang » en Arturo y yo (1984) y llega hasta los « e-mails » de Noche y Día (2005) y los « mensajes de texto » de Las cuatro estaciones (2008). En el mismo sentido, muchos de sus poemas están situados y fechados explícitamente. Sucede en casi todo Animaciones suspendidas (1986), que se aproxima así a una bitácora o diario, en poemas de La banda... (1994) y también en uno de sus poemas más brillantes, « Títere de la moneda » de Potlatch (2004), que comienza diciendo: "Pringles. 4 de enero de 2004. / Viene un chico a la puerta y grita desde afuera : / "Señor, ¿tiene una monedita ?". ${ }^{43}$ Irrupción de la economía en la lírica.

En todo caso, si de algún modo cupiera referirse a la mundanidad de Carrera sería sólo en uno de los sentidos etimológicos que habilita término « esnob » : contracción del latín « 
sine nobilitate ", $s /$ nob, sin nobleza. Podría hablarse de la mundanidad de Carrera como su forma de afirmar el campo amplio de los «no nobles » como territorio para su poesía, de situarse en el terreno de lo adolescente, de lo inmaduro e incompleto, de los que no saben, los no iluminados, no los poetas. "Arturito no sabe escribir $»^{44}$ dice uno de los versos más recordados de Arturo y yo. Frente a la lírica entendida como patrimonio y a partir de allí como la cofradía de aquellos que detentan esa herencia (una forma de " nobleza »), en Carrera la apertura y participación en mundos y paradigmas diversos lo convierte en un poeta lírico "sine nobilitate", uno que no aporta las credenciales de ejercitación técnica o el repertorio limitado de formas e imaginario, ni rechaza la heterogeneidad del presente en nombre de un idealismo, gesto necesario para sostener las nociones de interioridad y personalidad como islas separadas de lo histórico y lo colectivo. En cambio, asimila -en un gesto poco frecuente- notas de humor y anti-poesía que tuvieron poca presencia en el neobarroco y todavía menos en la lírica de las últimas décadas. Como señaló Chefjec, es un "poeta no-poeta » ${ }^{45}$. Vuelve sobre la idea de una poesía que pueda hablar prácticamente de cualquier cosa en esos chismeríos, murmullos, derivas, haciendo de ella antes un ámbito de escucha modulada y una forma de abordaje de la vida cotidiana que un género específico a « cultivar». Y aun dentro de esa amplitud, su atención va hacia lo menor : «-Contame sobre esas horas / que a vos te parecen nimias $»^{46}$, pide en el comienzo del poema «Apariencias defectuosas» en el que más adelante ironizará sobre las « poeticidades».

\section{5}

21 La obra de Carrera ha hecho de esta tensión o equilibrio uno de sus principales valores. Iniciada pocos años antes de que se instalara la dictadura cívico-militar en Argentina, se mantuvo al margen de lo público durante los años del régimen ${ }^{47} \mathrm{y}$ enfrentó los mismos problemas que las de sus contemporáneos: cómo articular una lengua poética en ese contexto y, luego, cómo rememorar en la post-dictadura. Su poética puede interpretarse también como respuesta a esos dilemas. Carrera parece haberse puesto en la tarea de forjar una lengua humana, donde las formas de apertura y referencialidad, incluso el uso de nombres propios de personas reales, impliquen una conexión del universo poético (cerrado, minorizado, ficticio de otro modo) con una realidad extra-poética, histórica y tangible. Un recurso que -por cierto- utilizó también a su manera Raúl Zurita en esos años. Se puede concebir así la poesía de Carrera como una lengua que trae memorias del goce, de las formas y la belleza clásicas incluso, pero que se (con)funde con lo cotidiano. Allí está acaso su nota más ominosa (lo que revela un libro como Arturo y yo, publicado en 1984 pero escrito en 1980 : que lo cotidiano puede seguir siendo bello en tiempos de horror: como dice un verso de Raúl Zurita, de 1979, "LA VIDA ES MUY HERMOSA, INCLUSO AHORA $\left.»{ }^{48}\right)$. Pero esa es también la nota menos proveniente de la tradición poética francesa de su modo de participar del neobarroco, ya que el trabajo con lo menor y lo cotidiano lo singularizan dentro de dicha constelación y lo conectan con la tradición materialista del influjo anglosajón en la poesía latinoamericana ${ }^{49}$ y así con las poéticas locales del Zeitgeist. Si la destrucción de los tejidos políticos, comunitarios y lingüísticos por las dictaduras de la región supuso una nueva impugnación del poder de la poesía, la de Carrera se propone como una poesía civil que, aun en un tono rumoroso, por elasticidad que no teme a lo que está de moda, busca el « elogio de la presencia » (como llamó a una entrevista que le realizaran ${ }^{50}$. Se trata de una oda o elegía, alternativamente, 
al todavía estar aquí, una celebración del aquí y ahora, donde hay algo de la voluntad de devolverle a la poesía aspectos del carácter de «lenguaje general » que, decía Roger Caillois, tenía en los orígenes cuando era sinónimo de memoria.

Cabría entonces por último corregir a Fogwill : Carrera no consigue una obra lograda " pese » a su atención hacia las modas y el presente. Más bien en el aprovechamiento de esa apertura en la obra -entre otros recursos- encuentra un modo de interrumpir el solipsismo de buena parte de la lírica contemporánea y, colocando su obra en relación con la vida cotidiana, no sólo despliega su voz sino cierta crónica o novela amplia y evanescente de lo social como trasfondo. La participación social, artística y experimental de Carrera dispersa su identidad de poeta en una identidad más amplia de artista. En su concepción de lo poético, ir a bailar, mezclarse con los más jóvenes, escuchar sus voces y sus dichos, así como hablar con un niño al borde de una pileta en el campo, son parte de la búsqueda de plenitud, del dar un paso en dirección a una lengua elástica, apta para hablar de todo y, ahora sí, en eso, estar un paso más cerca de los antiguos y de los resplandores poéticos originarios que los que buscan la iluminación en la mera imitación de algún pasado.

\section{BIBLIOGRAPHY}

Caillois, Roger. « Préface » en : Caillois, Roger, Lambert, Jean Clarence. Trésor de la poesie universelle. Paris : Gallimard, 1958.

Carrera, Arturo. «Introducción a Cómo escribí algunos libros míos » en : El niño Stanton, 1, Buenos Aires, septiembre de 2006, pág. 2-3.

Carrera, Arturo (comp.). Monstruos. Antología de la joven poesía argentina. Buenos Aires : FCE, 2001.

Carrera, Arturo. Vigilámbulo. Poesía reunida. Tres volúmenes. Buenos Aires : Adriana Hidalgo, 2014.

Chefjec, Sergio. «El estribillo de la experiencia » en : Carrera, Arturo. Vigilámbulo. Poesía reunida. Volumen I. Buenos Aires : Adriana Hidalgo, 2014. Págs. 11-53.

Fogwill. « Yo creía en el gusto » (entrevista por Daniel Freidemberg) en : Los libros de la guerra, Buenos Aires : Mansalva, 2008

Herrera, Ricardo, Tedesco, Luis. «Editorial » en : Hablar de Poesía, 1, 1999. Consultado el 17 enero 2017. URL : http://hablardepoesia.com.ar/numero1/editorial/

Jorge, Gerardo. El momento antipoético : tiempo de modernización (concepciones y usos de la tradición en la poesía concreta brasileña y en las obras de Nicanor Parra y Leónidas Lamborghini : 1950-1970). Mimeo. Tesis de doctorado (aprobada por la Universidad de Buenos Aires el 30-03-2015).

García Helder, Daniel. « El neobarroco en la Argentina », Diario de poesía, n 4, Buenos Aires, Rosario, Montevideo, otoño de 1987.

García Helder, Daniel, Prieto, Martín. « Boceto n 2 para un... de la poesía argentina reciente » en : Fondebrider, Jorge (comp.). Tres décadas de poesía argentina : 1976-2006. Buenos Aires : Libros del Rojas, 2006. Pág. 101-115. 
Link, Daniel. « La estación neobarroca » en : Carrera, Arturo. Las cuatro estaciones. Buenos Aires, Mansalva, 2008. Págs. 107-109.

Melchiorre, Valeria. « Como en filmina una dicha : la poesía de Arturo Carrera » en : Hablar de Poesía, 32, consultado el 17 enero 2017, URL : http://hablardepoesia.com.ar/numero-32/como-enfilmina-una-dicha-la-poesia-de-arturo-carrera-4/

Milán, Eduardo. « Parra y la poesía concreta », Diario de Poesía, 77, Buenos Aires, Rosario, diciembre de 2008-marzo de 2009, pág. 36-37.

Prieto, Martín. « Neobarrocos, objetivistas, epifánicos y realistas : nuevos apuntes para la historia de la nueva poesía argentina », Cahiers de LI.RI.CO [En línea], 3 | 2007, Puesto en línea el 01 julio 2012, consultado el 17 enero 2017. URL : http://lirico.revues.org/768; DOI : 10.4000/lirico.768

Prieto, Martín. « Ortiz en una disco », Diario de Poesía, nº 33, Buenos Aires, Rosario, otoño de 1995.

Usubiaga, Viviana. « Arturo y ellos. Diálogos entre la poesía de Arturo Carrera y la pintura contemporánea en la postdictadura argentina » en : Usubiaga, Viviana \& Longoni, Ana. Arte y literatura en la Argentina del siglo XX. Buenos Aires : Fundación Espigas, 2006.

Zurita, Raúl. Purgatorio. Santiago de Chile : Ed. Universitaria, 1979.

\section{NOTES}

1. La obra de Carrera es dividida por la crítica en dos etapas: una primera de libros más vanguardistas y barrocos (de Escrito con un nictógrafo de 1972, a Mi padre de 1985) y la segunda que abre Arturo y yo en 1984, interpretada como un giro que articula la impronta barroca con un tono «sencillista» y un tipo de poema más narrativo. El propio Carrera considera a Arturo y yo un punto de inflexión: a partir de allí y en forma sostenida durante los treinta años siguientes, consolidará una poética con un universo muy personal a la que está dedicado este artículo.

2. La obra de Carrera tiene un elemento autobiográfico sostenido que permite situar al yo de los poemas como una imagen del poeta dentro de la obra. Esta lectura se refuerza cuando se mencionan no sólo datos que conectan con la biografía del poeta sino nombres de personas cuya existencia real y conocimiento público terminan de apartar al texto de toda impronta puramente ficcional para situarlo en una relación compleja con el afuera, como meditación o elaboración sobre algo vivido.

3. Rosario Bléfari (Mar del Plata, 1965). Cantante, actriz y escritora argentina. Considerada una figura importante del rock independiente desde la década del noventa, cuando lideraba el grupo Suárez.

4. Carrera, Arturo. Vigilámbulo. Poesía reunida. Buenos Aires: Adriana Hidalgo, 2014. Volumen II., pág. 451. La totalidad de la poesía publicada por Carrera a la fecha, con excepción de un libro que salió en México en 2015 (Ritornelo de Malmö, México DF: Juan Malasuerte) está reunida en esta edición en tres volúmenes. A partir de aquí citaremos todos los pasajes de poemas de Carrera de esta edición.

5. Carrera, ibidem, II, p. 449.

6. Carrera, ibidem, II, p. 449. Los subrayados corresponden al texto original.

7. Carrera, ibidem, II, p. 452.

8. Carrera, ibidem, II, p. 449.

9. Gaspar Noé (Buenos Aires, 1963). Cineasta conocido por obras como Irreversible (2002) y Enter the Void (2009).

10. Carrera, op. cit., II, p. 455. Los subrayados corresponden al texto original. 
11. «Materiales de presente» es una categoría que propuse en mi tesis doctoral a partir de la categoría de «material» que propone Adorno en su Teoría estética. Propuse una distinción entre dos tipos posibles de materiales: genéricos y de presente. Cito la definición de la tesis: « (...) teniendo en cuenta que 'el material no es ningún material natural cuando se presenta en cuanto tal ante el artista, sino algo plenamente histórico' (Adorno [1971] 1983: 198), el concepto de Adorno nos permitirá plantear una distinción entre lo que llamaremos, por un lado, materiales de presente (entendiendo por esto aquellos que remitan de alguna forma al mundo contemporáneo a la producción de la obra en su estatuto históricamente específico, tanto por tratarse de técnicas o invenciones datadas en el período como por comportar carácter referencial) y, por otro, materiales genéricos (entendiendo por esto aquellos que no revelan una inscripción evidente en el momento de producción; y que, en general, tienden a formar parte de lo que se considera una configuración genérica estándar y heredada). En este sentido, la utilización o referencia a un hecho histórico puntual de su época de producción, en un poema, será considerado un ejemplo de 'material de presente', pero también lo serán la utilización de giros y léxico propios del habla de la época o incluso la adopción como tema de cuestiones en debate en un determinado período. En forma contrapuesta, los materiales que no permitan deslindar en sí mismos la pertenencia de la obra al momento de su producción, serán considerados 'genéricos'.» (Jorge, Gerardo. El momento antipoético: tiempo de modernización (concepciones y usos de la tradición en la poesía concreta brasileña y en las obras de Nicanor Parra y Leónidas Lamborghini: 1950-1970), mimeo, tesis doctoral, pág. 88-89).

12. La cuestión de la exhibición de una participación social ha sido señalada por Valeria Melchiorre en su muy atenta aunque por momentos tediosa y discutible reseña de la poesía reunida de Carrera. Allí, hablando de las redes afectivas y los intercambios que Carrera habría desarrollado, señala: «Es evidente (...) su habilidad a la hora de generar un entorno apto para los intercambios provechosos y fructíferos, datos éstos que son absorbidos peculiarmente por su escritura: '[...] no hace mucho le / dije a Emeterio [...]' (III, 301), leemos; y, el mismo fragmento de Artaud, que sirve de epígrafe a La partera canta de 1982, nos llega 'vía Severo Sarduy', 'vía César Aira' y 'via Haroldo de Campos', siempre con la cita escamoteada (III, 317), como si se nos revelara así la existencia de un círculo íntimo y privilegiado del que el autor forma parte.» (Melchiorre, Valeria. "Como en filmina una dicha: la poesía de Arturo Carrera» en: Hablar de Poesía, 32, consultado el 17 enero 2017, URL: http://hablardepoesia.com.ar/numero-32/como-enfilmina-una-dicha-la-poesia-de-arturo-carrera-4/)

13. García Helder, Daniel. «El neobarroco en la Argentina», Diario de poesía, n 4, Buenos Aires, Rosario, Montevideo, otoño de 1987.

14. Dice Fogwill: «entre los vivos, sólo encuentro una obra tan admirable como la de Leónidas, y es la de Arturito. Y sabrás que no hay nadie tan cholulo y cortesano como él. Esto indica que no siempre la conciliación con los aparatos de humillación del salón literario afecta los instrumentos de producción de la obra». Y más adelante: «En la poesía tiene que haber una verdad, una verdad, ponele comillas, 'íntima'. Esa verdad que aparece en Arturo Carrera: Arturo es un personaje de superficie absoluta, es un dandy, y sin embargo su poesía es una poesía de verdad, no hay sentimiento fabricado, ni citado». (Fogwill. "Yo creía en el gusto (entrevista de Daniel Freidemberg)» en: Los libros de la guerra. Buenos Aires, Mansalva, 2008, pág. 281 y 286).

15. Fogwill, op. cit., pág. 286.

16. «El carácter reservado de Carrera a veces es interpretado como timidez. Probablemente haya algo de eso, pero sería una timidez mundana, el precio que cada uno se impone para interactuar con los demás» (Chefjec, Sergio. «El estribillo de la experiencia» en: Carrera, op. cit., I, pág. 15).

17. Melchiorre, op. cit.

18. Prieto, Martín. «Ortiz en una disco», Diario de Poesía, nº 33, Buenos Aires, Rosario, otoño de 1995. 
19. Cfr. «Lyric» en: Greene, Roland (ed.). The Princeton enciclopedia of poetry and poetics. Fourth edition. Princeton: Princeton University Press, 2012.

20. Milán, Eduardo. «Parra y la poesía concreta», Diario de Poesía, 77, Buenos Aires, Rosario, diciembre de 2008-marzo de 2009, pág. 36-37. Sobre este eje y la gravitación en los años cuarenta en toda América Latina de una concepción de la poesía refractaria al presente como fuente de materiales y objeto de interés, me explayo en mi tesis doctoral a propósito del llamado «retorno al orden».

21. En la nota editorial del primer número de Hablar de Poesía, de 1999, Herrera y Tedesco dicen: «En gran medida, poesía y crítica no constituyen aún géneros literarios socializados. Se diría, incluso, que casi han desaparecido como tales. El panegírico y la difamación, la pedantería y el facilismo, siguen muchas veces ocupando el lugar que les corresponden al uso artístico del lenguaje y al pensamiento (...) la distancia que va de la antipoesía a la poesía es demasiado grande como para pretender salvarla con un mero acuerdo formal. El futuro es incierto y complejo (...) No sólo la poesía entendida como arte de la palabra ha sido falseada por el experimentalismo gratuito, sino que también la sensibilidad poética está siendo malversada al ubicarse a la zaga de la insignificancia, del vértigo publicitario de la época. A pesar de ello, creemos que un primer paso para superar la heterogeneidad disolvente de la poesía argentina de hoy (que sólo un optimismo irresponsable o interesado puede confundir con variedad y exuberancia) es el de convocar a todas las tendencias en pugna a una confrontación de ideas que ponga a prueba la validez de los distintos ángulos de visión que actualmente tornan tan confusa la identidad del fenómeno poético.» (Herrera, Ricardo, Tedesco, Luis. «Editorial» en: Hablar de Poesía, 1, 1999. Consultado el 17 enero 2017. URL: http://hablardepoesia.com.ar/numero1/editorial/ )

22. Existen, de hecho, varios estudios al respecto y uno de los más recientes ha sido publicado en esta revista: Prieto, Martín. «Neobarrocos, objetivistas, epifánicos y realistas: nuevos apuntes para la historia de la nueva poesía argentina», Cahiers de LI.RI.CO [En línea], 3 | 2007, Puesto en línea el 01 julio 2012, consultado el 17 enero 2017. URL: http://lirico.revues.org/768 ; DOI : 10.4000/lirico.768

23. No es casual que Melchiorre, en Hablar de Poesía, al analizar la inclusión de voces y materiales «en bruto» que es uno de los procedimientos de Carrera, diga que «sucumbe aquí cierta concepción acerca de la belleza, aunque, lo que es más importante, se pierde la vacilación de un sentido. Porque la carga de lo dicho anula, paradójicamente, otra densidad: la de lo ambiguo» (Melchiorre, op. cit.).

24. En un citado artículo de Daniel García Helder y Martín Prieto publicado originalmente en Punto de Vista en 1998, se propone como criterio para identificar a la «poesía de los noventa» ese privilegiar la relación con el presente por sobre el vínculo con la tradición. Helder y Prieto postulan que los poetas de esta generación «a una típica y dilatada ligazón con el pasado literario, prefieren una corta, intensa, heterodoxa, no predeterminada, esporádica. Son poetas de la sincronía. Ya no pretenden tener, o no se conforman con tener, una conciencia acabada de la poesía universal, como los poetas de las generaciones anteriores. Su coeficiente artístico no deberá medirse, por lo tanto, por su nivel cultural ni por el largo de sus raíces en la tradición, sino más bien por su grado de aprehensión del Zeitgeist y su capacidad de transformarlo en arte concreto: versos, estrofas, imágenes, escenas, delirios» (García Helder, Daniel, Prieto, Martín. «Boceto $n^{\circ} 2$ para un... de la poesía argentina reciente» en: Fondebrider, Jorge (comp.). Tres décadas de poesía argentina: 1976-2006. Buenos Aires: Libros del Rojas, 2006. Pág. 105-106).

25. Rubio, Alejandro. «Ars poetica» en: Carrera, Arturo. (comp.) Monstruos. Antología de la joven poesía argentina. Buenos Aires: FCE, 2001. Pág. 160.

26. Carrera, op. cit., II, pág. 387.

27. Carrera, op. cit., II, pág. 509.

28. Carrera, op. cit., II, pág. 461.

29. Carrera, op. cit. , II, p. 448. 
30. Carrera, op. cit., II, pág. 369.

31. Carrera, op. cit., I, pág. 370.

32. Carrera, op. cit., II, pág. 593.

33. Cfr. Carrera, Arturo. «Introducción a Cómo escribí algunos libros míos», El niño Stanton, 1, Buenos Aires, septiembre de 2006, pág. 2-3.

34. Carrera, op. cit., II, págs. 423-424.

35. Carrera, op. cit., III, pág. 237.

36. En Potlatch, en una práctica que hace del poeta casi un sociólogo o antropólogo, se incluyen «datas»: prosas que derivan de testimonios tomados oralmente por el poeta a distintas personas acerca de la cuestión que vertebra el libro: su relación con el dinero en la infancia.

37. Carrera, op. cit., II, pág. 321.

38. Carrera, op. cit., I, pág. 387.

39. Carrera, op. cit., I, pág. 579.

40. Chefjec, op. cit., pág. 24. Tiene gracia el planteo de Chefjec que señala esto sobre la característica voz real (física) del poeta para luego llevar el análisis hacia la idea de que algo de esa impronta «sucia» de su voz pasa a su poética.

41. Esta falta de solipsismo ha sido señalada por Daniel Link en el epílogo al libro Las cuatro estaciones, titulado «La estación neobarroca». Dice Link refiriéndose a lo que entiende como un «doble centro que organiza el registro poético» de este libro de 2008: «el poema se instala en el umbral de poiesis-politikós que siempre lo caracterizó, y desdeña todo solipsismo» (Link, Daniel. «La estación neobarroca» en: Carrera, Arturo. Las cuatro estaciones. Buenos Aires: Mansalva, 2008. Pág. 107-108).

42. Para un abordaje de los vínculos y colaboraciones que Carrera mantiene con artistas visuales en los años ochenta, cfr. Usubiaga, Viviana. «Arturo y ellos. Diálogos entre la poesía de Arturo Carrera y la pintura contemporánea en la postdictadura argentina» en: Usubiaga, Viviana \& Longoni, Ana. Arte y literatura en la Argentina del siglo XX. Buenos Aires: Fundación Espigas, 2006.

43. Carrera, op. cit., I, pág. 674.

44. Carrera, op. cit., III, pág. 237.

45. Chefjec, op. cit., pág. 18.

46. Carrera, op. cit., II, pág. 418.

47. Carrera no publica libros entre 1975 (Oro) y 1982 (La partera canta).

48. Zurita, Raúl. Purgatorio. Santiago de Chile: Ed. Universitaria, 1979. Pág. 9.

49. Se diría que al recuperar ese gesto propio de William Carlos Williams (poeta al que Carrera cita más de una vez) de centrarse en escenas pequeñas y cotidianas, hay en Carrera un doble materialismo: su obra parte de un materialismo del lenguaje en los comienzos (herencia de la línea que baja del concretismo al neobarroco) y llega a una suerte de materialismo social de los usos de la lengua que computa y recolecta y por los cuales se interesa como objeto.

50. La entrevista a la que se accede desde el hipervínculo forma parte del ciclo Audiovideoteca de Escritores: "Obra en Construcción: Arturo Carrera". https://www.youtube.com/watch? v=yEg180hWLN0 [consultado el 28 mayo 2017] 


\section{ABSTRACTS}

This article proposes a reading of the work of the argentine poet Arturo Carrera, centered in the stage that begins with Arturo y yo in 1984. It starts analyzing the role played in it by a set of materials and dissonant references for the imaginary of the argentine lyrical poetry of its moment of production. It analyzes what can be considered cultural and academic "fashions", sociolectal uses of language of young people and the inscription of a network of names that refers to a participation in an avant-garde artistic community, among other materials characterized as "present materials", discussing some images that the critic built around Carrera and the neo-baroque in relation to ideas such as frivolity, superficiality, snobbery. The hypothesis proposed is that these and other notes and materials play a defining role in the constitution of a porous, non-monological lyrical poetry inscribed in the present and away from all solipsism and notion of "purity", which is difficult to classify in the local poetic panorama, given its distance also to the Zeitgeist poetics that were contemporary to him and that argued with the traditionalist lyric.

Este artículo propone una lectura de la obra del poeta Arturo Carrera, centrada en la etapa que se inicia con Arturo y yo en 1984, a partir de un análisis del rol que juegan en ella un conjunto de materiales y referencias disonantes para el imaginario de la lírica argentina de su momento de producción. Se analizan lo que pueden considerarse marcas de «modas» culturales y académicas, usos sociolectales de la lengua que remiten a los jóvenes y la inscripción de una red de nombres propios que trasunta la participación en una comunidad artística de avanzada, entre otros materiales que se caracterizan como «de presente ", revisando algunas imágenes que la crítica construyó alrededor de Carrera y del neobarroco en relación con ideas como frivolidad, superficialidad, esnobismo. Se propone la hipótesis de que esas y otras disonancias en su obra cumplen un rol definitorio en la constitución de una poesía lírica porosa, no monológica, inscripta en el presente y alejada de todo solipsismo y noción de "pureza ", de difícil encasillamiento en el panorama local, dada su distancia también respecto de las poéticas fundadas en el Zeitgeist que le fueron contemporáneas y polemizaron con la lírica tradicionalista.

Cet article propose une lecture de l'œuvre du poète argentin Arturo Carrera, concentré sur l'étape qui commence avec Arturo y yo en 1984, à partir d'une analyse du rôle joué par une série de matériels et références dissonantes à l'imaginaire de la poésie lyrique de l'Argentine du temps de production. On analyse ce qui peut être considéré comme des marques de "mode" culturels et académiques, des usages sociolectales du langage qui se réfèrent aux jeunes et l'enregistrement d'un réseau de noms qui font référence à la participation à une communauté artistique d'avantgarde, entre autres matériaux caractérisés comme étant "matériaux du présent". On examine des images que la critique a construit autour de Carrera et le neo-baroque concernant des idées comme frivolité, superficialité, snobisme. L'hypothèse principale est que ces notes et les matériaux, ainsi que d'autres, jouent un rôle décisif dans la création d'une poésie lyrique pas monologique, enregistrée dans le présent et loin de tout solipsisme et notion de "pureté ", qui est difficile à classer dans le panorama poétique local, étant donné la distance aussi par rapport à la poétique fondée sur l'esprit du temps qui était contemporain et rejetait la poésie lyrique traditionaliste. 
INDEX

Mots-clés: Carrera mode présent poésie lyrique

Keywords: Carrera fashion present poetry lyric

Palabras claves: Carrera moda presente poesía lírica

\section{AUTHOR}

\section{GERARDO JORGE}

UBA / UNA / CONICET

gerardjorge@yahoo.com.ar

Poeta, Doctor en Literatura (UBA), Profesor adjunto Cátedra « Poesía universal I » (UNA). 